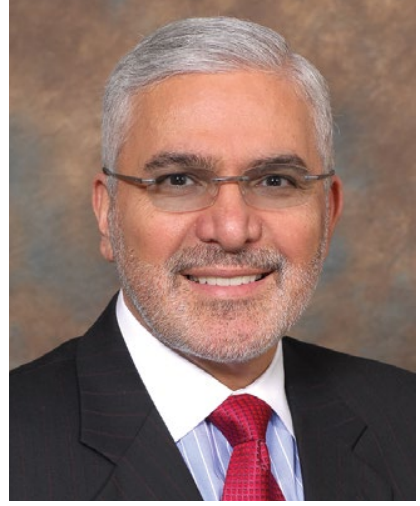

Henry A. Nasrallah, MD

Editor-in-Chief

doi: 10.12788/cp.0184

\title{
I have a dream ... for psychiatry
}

One of the most inspiring speeches ever made is Rev. Martin Luther

King's "I have a dream" about ending discrimination and achieving social justice. Many of the tenets of that classic speech are relevant to psychiatric patients who have been subjected to discrimination and bias instead of the compassion and support that they deserve, as do patients with other medical disorders.

\section{I have come to see the world through the eyes of suffering psychiatric patients, and I have a dream to provide them with the compassion and support that they deserve}

Like Rev. King, we all have dreams, spoken and unspoken. They may be related to our various goals or objectives as individuals, spouses, parents, professionals, friends, or citizens of the world. Here, I will elaborate on my dream as a psychiatric physician, educator, and researcher, with decades of experience treating thousands of patients, many of whom I followed for a long time. I have come to see the world through the eyes and painful journeys of suffering psychiatric patients.

\section{Vision of a better world for our patients}

So, here is my dream, comprised of multiple parts that many clinicianreaders may have incorporated in their own dreams about psychiatry. I have a dream:

- that the ugly, stubborn stigma of mental illness evaporates and is replaced with empathy and compassion

- that genuine full parity be implemented for all psychiatric patients
- that the public becomes far more educated about their own mental health, and cognizant of psychiatric symptoms in their family members and friends, so they can urge them to promptly seek medical help. The public should be aware that the success rate of treating psychiatric disorders is similar to that of many general medical conditions, such as heart, lung, kidney, and liver diseases

- that psychiatry continues to evolve into a clinical neuroscience, respected and appreciated like its sister neurology, and emphasizing that all mental illnesses are biologically rooted in various brain circuits

- that neuroscience literacy among psychiatrists increases dramatically, while maintaining our biopsychosocial clinical framework

- that federal funding for research into the causes and treatments of psychiatric disorders increases by an order of magnitude, to help accelerate the discovery of cures for disabling psychiatric disorders, which have a serious personal, societal, and financial toll

- that some of the many fabulously wealthy billionaires in this country (and around the world) adopt psychiatry as their favorite charity, and establish powerful and very well-funded research foundations to explore the brain and solve its mysteries in health and disease

- that effective treatments for and interventions to prevent alcohol and substance use disorders are discovered, including vaccines for alcoholism and other drugs of abuse. This would save countless lives lost to addiction 
- that Medicare opens its huge wallet and supports thousands of additional residency training positions to address the serious shortage of psychiatrists

- that pharmaceutical companies, admittedly the only entities with the requisite infrastructure to develop new drugs for psychiatry, be creatively incentivized to discover drugs with new mechanisms of action to effectively treat psychiatric conditions for which there are no FDA-approved medications, such as the negative symptoms and cognitive deficits of schizophrenia, personality disorders (such as borderline personality), autism, and Alzheimer's disease

- that the jailing, incarceration, and criminalization of patients with serious mental illness ceases immediately and is replaced with hospitalization and dignified medical treatment instead of prison sentences with murders and rapists. Building more hospitals instead of more prisons is the civilized and ethical approach to psychiatric brain disorders

- that the public recognizes that persons suffering from schizophrenia are more likely to be victims of crime rather than perpetrators. Tell that to the misguided media

- that clinicians in primary care specialties, where up to $50 \%$ of patients have a diagnosable and treatable psychiatric illness, be much better trained in psychiatry during their residency. Currently, residents in family medicine, general internal medicine, pediatrics, and obstetrics/gynecology receive 0 months to 1 month of psychiatry in their 4 years of training. Many are unable to handle the large number of psychiatric disorders in their patients. In addition, psychiatrists and primary care physicians should be colocalized so psychiatric and primary care patients can both benefit from true collaborative care, because many are dually afflicted

- that the syndemic ${ }^{1}$ (ie, multiple epidemics) that often increases the risk of psychiatric disorders is effectively addressed for the sake of our patients and society at large. The ongoing syndemic includes poverty, child abuse, human trafficking, domestic violence, racism, suicide, gun violence, broken families, and social media addiction across all ages

- that psychiatric practitioners embrace and adopt validated rating scales in their practice to quantify the severity of the patient's illness and adverse effects at each visit, and to assess the degree of improvement in both. Measurement is at the foundation of science. Psychiatry will be a stronger medical specialty with measurementbased practice

- that licensing boards stop discriminating against physicians who have recovered from a psychiatric disorder or addiction. This form of stigma is destructive to the functioning of highly trained medical professionals who recover with treatment and can return to work

- that the number of psychiatric hospital beds in the country is significantly expanded to accommodate the high demand, and that psychiatric wards in general hospitals not be repurposed for more lucrative, procedure-oriented programs

- that insurance companies stop the absurdity of authorizing only 3 to 4 days for the inpatient treatment of patients who are acutely psychotic, manic, or suicidally depressed. It is impossible for such serious brain disorders to improve rapidly. This leads to discharging patients who are still unstable and who might relapse quickly after discharge, risking harm to themselves, or ending up in jail

- that HIPAA laws are revised to allow psychiatrists to collect or exchange information about ailing adult members of the family. Collateral information is a vital component of psychiatric evaluation, and its prohibition
Editorial Staff

EDITOR Jeff Bauer

SENIOR EDITOR Sathya Achia Abraham ASSISTANT EDITOR Matthew Wyles

WEB EDITOR Kathryn Wighton

Art \& Production Staff

CREATIVE DIRECTOR Louise Koenig

ART DIRECTOR Pat Fopma

DIRECTOR, JOURNAL MANUFACTURING Michael Wendt

PRODUCTION MANAGER Donna Pituras

Publishing Staff

PUBLISHER Sharon Finch

DIRECTOR EBUSINESS DEVELOPMENT Alison Paton

SENIOR DIRECTOR OF SALES

Tim LaPella

Editor-in-Chief Emeritus

James Randolph Hillard, MD

Frontline Medical Communications VP, SALES Mike Guire

VP, DIGITAL CONTENT \& STRATEGY Amy Pfeiffer

PRESIDENT, CUSTOM SOLUTIONS JoAnn Wahl

CIRCULATION DIRECTOR Jared Sonners

In affiliation with Global Academy for Medical Education, LLC

PRESIDENT David J. Small, MBA

\section{FRONTLINE MLedge}

7 Century Drive, Suite 302

Parsippany, NJ 07054

Tel: (973) 206-3434

Fax: (973) 206-9378

www.frontlinemedcom.com

Subscription Inquiries: subscriptions@mdedge.com

Published through an educational partnership with

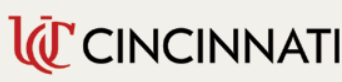




\section{Exciting Opportunity for Psychiatrists in the Beautiful Southwest}

San Juan Health Partners in Farmington, New Mexico is recruiting one General Psychiatrist and one experienced Psychiatrist with potential for Medical Directorship. Join a caring, community hospital in the heart of the Four Corners.

You can look forward to:

- Compensation range based on years of experience

- Less than two years of experience $\$ 250,000$ - $\$ 255,000$

- Two or more years of experience $\$ 295,000$ - $\$ 300,000$

- 1:4 call

- Productivity/quality bonus potential

- Lucrative benefit package, including retirement

- Student loan repayment and residency stipend

- Competitive sign on bonus and relocation package

- Quality work/life balance

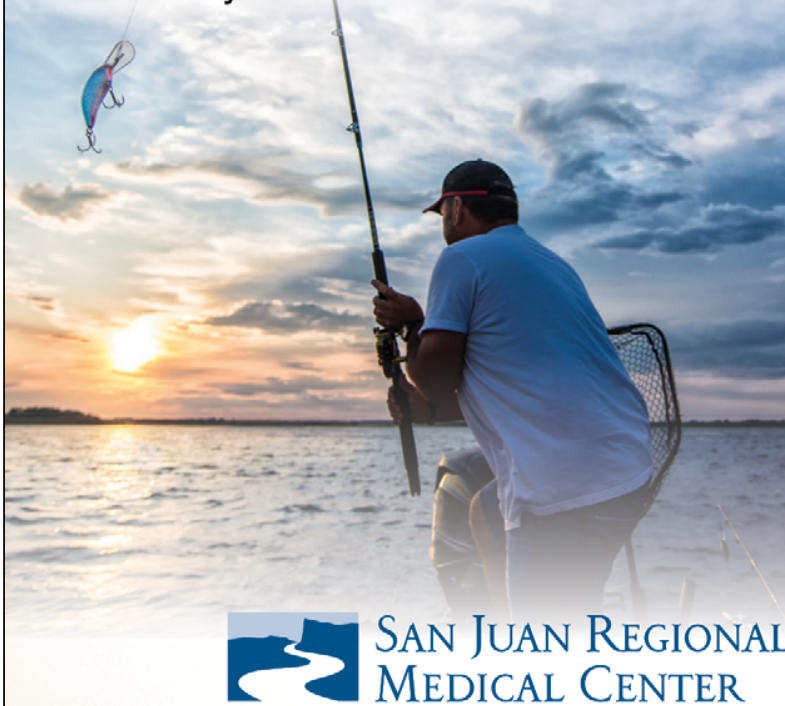

Interested candidates should address their C.V. to:

Terri Smith | tsmith@sjrmc.net

888.282.6591 or 505.609 .6011

sanjuanregional.com | sjrmcdocs.com

San Juan Regional Medical Center is a non-profit and community governed facility. Farmington offers a temperate four-season climate near the Rocky Mountains with worldclass snow skiing, fly fishing, golf, hiking and water sports. Easy access to world renowned Santa Fe Opera, cultural sites, National Parks and monuments. Farmington's strong sense of community and vibrant Southwest culture make it a great place to pursue a work-life balance. can be harmful to the patient. The family often is the most likely support system for the mentally ill individual, and must be informed about what their family member needs after discharge

- that long-acting antipsychotics are used very early and widely to prevent the tragic consequences of psychotic relapses, ${ }^{2}$ and long-lasting antidepressants are developed to prevent the relapse and risk of suicide in many patients who stop their antidepressant medication once they feel better, and do not recognize that like hypertension or diabetes, depression requires ongoing pharmacotherapy to prevent relapse

- that the time to get a court order for involuntary administration of antipsychotic medication to acutely psychotic patients is reduced to 1 day because a large body of published evidence shows that a longer duration of untreated psychosis has a deleterious neurotoxic effect on the brain, worsening outcomes and prognosis. ${ }^{3}$ The legal system should catch up with scientific findings.

Just as Martin Luther King's dream resonated loudly for decades and led to salutary legal and societal changes, I hope that what I dream about will eventually become reality. My dream is shared by all my fellow psychiatrists, and it will come true if we unite, lobby continuously, and advocate vigorously for our patients and our noble profession. I am sure we shall overcome our challenges someday.

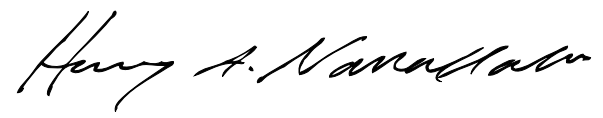

\section{Henry A. Nasrallah, MD}

Editor-in-Chief

\section{References}

1. Namer Y, Razum O. Surviving syndemics. Lancet. 2021; 398(10295):118-119.

2. Nasrallah HA. 10 devastating consequences of psychotic relapses. Current Psychiatry. 2021;20(5):9-12.

3. Perkins DO, Gu H, Boteva K, et al. Relationship between duration of untreated psychosis and outcome in firstepisode schizophrenia: a critical review and meta-analysis. Am J Psychiatry. 2005;162(10):1785-1804. 